\title{
Analysis Method of Internet Advertising-Marketing Information's Dynamic Changes
}

\author{
Kamala.K.Hashimova \\ Institute of Information Technology of Azerbaijan National Academy of Sciences, Baku, Azerbaijan \\ Email: kama25@mail.ru, multimedia@iit.science.az
}

Received: 27 April 2017; Accepted: 05 June 2017; Published: 08 September 2017

\begin{abstract}
In the article internet advertising-marketing information's dynamic changes, indicator parameters of that characterizes effectiveness of internet advertising campaign have been analysed. For evaluation of advertising activities, analysis of dynamic changes to obtain and calculation values of selective parameters have been researched. In equal time intervals obtained values from indicator parameters that is obtained with their values value matrix can be created. In order to eliminate inequal time intervals it is recommended interpolated operations should be conducted. Therefore, by selecting parameters which have statistical communication, through using experimental values of these parameters model has been established for evaluation of effectiveness of Internet advertising campaign.
\end{abstract}

Index Terms - Internet advertising marketing, effectiveness parameters, indicator vectors, Matrix of effectiveness parameters, integral indicator parameter, measure of dynamic change

\section{INTRODUCTION}

It is known that, one of the tools to providesuccess of electron trade is organising Internet advertising works. Large companies working in the fields of manufacturing, logistic, services are interested in deliver goods and services that they want to advertise by using electronic tools to potential customers and for this purpose they spend a lot of money [1]. Even, development of seperate economic districts, especially provision of development of tourism sector one of the tools is Internet advertis about region [2]. Advertisement creators also interested in rising quality and success of their products. Main part of Internet advertising carried out by Web sites. Analysis of electronic trade and Internet advertising marketing works, information related to every advertising companies are subject to dynamic changes [3].

The first parameter used in evaluations of appeals to sites in which advertising materials placed and effectiveness of Internet advertising is hits. Hit is appeal to web server in order to buy any advertising file. At this time the computer that sends order to web server and has unique address is called host. For a site during unit time number of sent hits indicates advertisement power. Besides hits and hosts influence of other advertising information to potential users auditorium is measured by such CTR (Clickthroughrate), CTB (Click-To-Buy),CTI (Click-ToInterest),VTR (View-Trough-Rate), CPV- (Cost per Visit) va CPUU- (Cost per unique user) and other relative effectiveness indicators [4-6].

In order to evaluate of advertisement effectiveness and form various necessary indicators datas are obtained by different methods and tools [7]. In many cases for this purpose counters that provided in advertising sites can be used. Through these counters number of appeals to Internet tools in which advertising information is $\operatorname{placed}\left(\mathrm{N}_{\text {visitors }}\right.$ parameter that shows general number of appeals to specific site), repeated appeals number (for specific site $\mathrm{N}_{\text {interest }}$ parameter) that highly interested to advertising site to get information about advertised goods and services can be obtained. Some counters can be created via analysis of $\log$ files of servers.

Parameters that indicates effectiveness of advertising avtivities and indicated all above can be analyzed one by one. However, advertising activities can be corrected on the basis of combined analysis of correlated parameters.

Beside it, as advertisement orderer companies that offer goods and services can create Data Bases which is about potential customers. In these bases, users surveys, registered IP adressesand other beneficial information can be collected. For this purpose calls of customer calls, orders, contracts, selling operations information also can be used.

The following factors can affect Internet advertising indicators:

Pictures and information that arouse interest in people looking to site in advertisement text.

Determination of effective volume of advertisement materials.

Observation by voice and movement.

Interactivity of advertisement. Advertisement materials that are reacted to cursor movement on it are very interested.

Advertisement place in Web site. 
Purposefullness. Characteristics of appealed auditorium ( age, gender, education and etc. ) should be taken into consideration

Companies that deal with manufacturing, selling, logistics and etc. adressing the need of production and by desire to earn success, implements special methods and algorithms in order to learn various parameters of Internet advertising, especially dynamic changes parameters. In this field intensity of conducted works reveals that analogical issues will remain as actual.

The article devoted method for analysis of dynamic changes of parameters that are characterized Internet advertising marketing's information.

\section{FORMULATION OF THE PROBLEM}

As mentioned above, one of the main indicators of Internet advertising'effectiveness is CTR (Clickthroughrate). This indicator is the percentage define of ratio of users who use special links that inform wider (passport data, user manual, technical characteristics and etc.) about goods and services being in advertisement site and advertised goods and services to the number of the whole users who looks the site.It shows effectiveness of online advertisement campaign. Same opinion can be considered in advertisement by e-mail tool. Here CTR is the ratio of number of using analogical links in E-mail to the number of Emails.

$$
\mathrm{CTR}=\frac{\mathrm{N}_{\text {click }}}{\mathrm{N}_{\text {view }}}
$$

Here $\mathrm{N}_{\text {click }}$ is number of using special links, $\mathrm{N}_{\text {view }}$ is number of lookers to advertisements. In many cases this parameter is defined as percentage.

In internet advertisement second main indicator is CTB(Click-To-Buy) parameter. This parameter is the ratio of number of users who decide to be advertised goods or services to the number whole lookers to the site.

$$
\text { CTB }=\frac{\mathrm{N}_{\text {clients }}}{\mathrm{N}_{\text {visitors }}}
$$

Here $\mathrm{N}_{\text {clients }}$ is the number of people who decide to buy advertised good or services. $\mathrm{N}_{\text {visitors }}$ number of people who look to the site. This indicator of effectiveness of internet advertising is sometimes called as conversion coefficient that site lookers to the buyers. For this indicator being attractive of the offering form of goods or services is very important.

CTI (Click-To-Interest)- parameter is measured by number of people who look to their interested advertisement to the number of the people who look to advertisement.

$$
\text { CTI }=\frac{\mathrm{N}_{\text {interest }}}{\mathrm{N}_{\text {visitors }}}
$$

Here $\mathrm{N}_{\text {interest }}$ parameter shows number of people interested in advertisement site. This parameter is formed from number of users who look some pages of the site, look repeatly to the site, and want to get extra information about advertised goods or services, request communication adresses and save. $\mathrm{N}_{\text {visitors }}$ is number of all lookers to the site.

VTR (View-Trough-Rate) parameter characterizes subjective attractivity of Internet advertisement and is measured by the ratio of number of lookings to the advertisement to the number of number of indicated advertisement.

In some cases parameters are used as value of every entering to the advertisement site and value of every unique users' entering to advertisement site. Firts parameter is the ratio of cost expended to advertisement to the number of enterings to the Web-site. It is possible that, in certain time interval a user appeal more than one time. As unique user is related to IP adresses, repeated appeals can not be taked into consideration. Therefore, second parameter is more important. These parameters also dynamically changes during advertisement campaign and it may be crucial to control the changes. The low values of these parameters creates hopes to generate revenue quichly obtained from costs expended to advertisement. Value of every appealing to the advertisement site

is calculated as $\mathrm{CPV}=\frac{\mathrm{C}}{\mathrm{V}}$. Here

CPV- (Cost per Visit) is the value of appealing to advertisement site.

$\mathrm{C}$ - price of placing advertisement.

$\mathrm{V}$ - number of appeals to advertisement site.

Price of entering of every unique user. Here as calculated

$$
\mathrm{CPUU}=\frac{\mathrm{C}}{\mathrm{UU}}
$$

Here CPUU- (Cost per unique user) is the price of appeling of unique user to the site.

$\mathrm{C}-$ is the price of placing advertisement.

$\mathrm{UU}$ - is number unique users. When saying Unique users it is considered having IP address and can be determined user. In Cambridge Business English dictionary it is determined someone who looks at a website one or more times in a particular period of time, and who can be recognized by the address of their computer.

For evaluation of advertisement activity effectiveness and indication of necessity of financial fund spent on the field of company that carries out advertisement methods have been developed $[8,9]$.

In order to evaluate effectoveness of advertisement avtivites and dynamical changes of parameters that characterize it, at first step in measurement or calculation of the parameters accuracy and series should be achieved. 
Beside, mathematical devises should be implemented for objectivity of analysis of obtained information. According to advertised goods and services beside parameters indicated above, volume of selling products, number of contracts and etc. such parameters should be controlled before advertisement campaign, during advertisement campaign, at the end of the advertisement campaign. For this purpose:

Obtaining or calculation of parameters should be done in equal time intervals and time series should be created from values of parameters;

Being or not being statistical communication between parameters that are written as time series should be evaluated by various criterias. Parameters that have accordance communications should be selected for analysis;

Selected parameters' obtained origin and methods' necessity, confidence coefficient should be created;

In necessary cases, from obtained parameters integral effectivity parameter can be created and from this integral parameter time serie can be created.

In the article the solution for cited issues is put forward.

\section{Setting UP Parameters'VAlue Matrices}

Assume that, $\mathrm{N}$ number of indicator parameter for analysis of dynamic changes of Internet advertisingmarketing information are involved. From each of these indicators, being $\Delta \mathrm{h}$ time intervals among them, values are obtained or calculated. Thereby, by certain $\mathrm{T}=\mathrm{M} * \Delta \mathrm{h}$, in $[0, \mathrm{~T}]$ time range, from every selected parameters $\mathrm{M}$ number of values can be obtained. Due to $\mathrm{N}$ number of selected parameters for every $n \in[1, N]$ these values creates $\mathrm{P}_{\mathrm{n}}$ vector.

$P_{n}=\left(P_{n 1}, P_{n 2}, \ldots P_{n M}\right)$

Here $P_{n m} n \in[1, N], m \in[1, M] m$-th value of $n$-th parameter

With values of the selected parameters

$$
\mathrm{P}=\left(\begin{array}{ccc}
\mathrm{P}_{11} & \cdots & \mathrm{P}_{1 \mathrm{M}} \\
\vdots & \ddots & \vdots \\
\mathrm{P}_{\mathrm{N} 1} & \cdots & \mathrm{P}_{\mathrm{NM}}
\end{array}\right)
$$

Creates parameters matrice.

Assume that, for any $n \in[1, N]$ values of $P_{n}$ parameter obtained by time series that are different from $\Delta \mathrm{h}$ time interval. If these different time breaks are not much different from $\Delta \mathrm{h}$ time breaks appropriate values vector can be brought to vector that has $\Delta \mathrm{h}$ breaks between their values by interpolation. For this pupose note the followings:

Values vector of parameters of which time intervals between them different from $\Delta \mathrm{h}$ time interval as $\mathrm{P}_{\mathrm{n}}^{\mathrm{f}}=$ $\left(\mathrm{P}_{\mathrm{n} 1}^{\mathrm{f}}, \mathrm{P}_{\mathrm{n} 2}^{\mathrm{f}}, \ldots, \mathrm{P}_{\mathrm{nM}}^{\mathrm{f}}\right)$;

Let's denote time interval between this vector's $i^{\text {th }}$ and $(\mathrm{i}+1)^{\text {th }}$ values with $\Delta \mathrm{h}_{\mathrm{i}}^{\mathrm{f}}$. On the condition of $\mathrm{J} * \Delta \mathrm{h} \in$ $\left[\sum_{\mathrm{m}=1}^{\mathrm{M}-1} \Delta \mathrm{h}_{\mathrm{m}}^{\mathrm{f}}, \sum_{\mathrm{m}=1}^{\mathrm{M}} \Delta \mathrm{h}_{\mathrm{m}}^{\mathrm{f}}\right]$ for arbitrary $\mathrm{J}$ we can write:
For $\mathrm{m}=1, \mathrm{P}_{\mathrm{n} 1}=\mathrm{P}_{\mathrm{n} 1}^{\mathrm{f}}$, for $\forall \mathrm{m} \in[2, \mathrm{~J}]$

$$
\begin{aligned}
& \mathrm{P}_{\mathrm{nm}}=\left\{\begin{array}{c}
\mathrm{P}_{\mathrm{nk}}^{\mathrm{f}}, \text { if there is } \exists \mathrm{k}, \quad \mathrm{m} * \Delta \mathrm{h}=\sum_{\mathrm{i}=1}^{\mathrm{k}} \Delta \mathrm{h}_{\mathrm{i}}^{\mathrm{f}} \\
\frac{\mathrm{P}_{\mathrm{n}(\mathrm{k}-1)}^{\mathrm{f}}\left[\mathrm{m} * \Delta \mathrm{h}-\sum_{\mathrm{i}=1}^{\mathrm{k}} \Delta \mathrm{h}_{\mathrm{i}}^{\mathrm{f}}\right]+\mathrm{P}_{\mathrm{nk}}^{\mathrm{f}}\left[\sum_{\mathrm{i}=1}^{\mathrm{k}} \Delta \mathrm{h}_{\mathrm{i}}^{\mathrm{f}}-\mathrm{m} * \Delta \mathrm{h}\right]}{\Delta \mathrm{h}_{\mathrm{k}}^{\mathrm{f}}}, \mathrm{m} *
\end{array}\right. \\
& \text { * } \Delta h \in\left[\sum_{i=1}^{k-1} \Delta h_{i}^{f}, \sum_{i=1}^{k} \Delta h_{i}^{f}\right]
\end{aligned}
$$

After interpolated operation on every parameter vector, for writing parameter matrices from every vector starting from last element equal number of elements should be taken. This number is determined as remained minimum number from after interpolation process of elements in the vectors. Thereby, from every $\mathrm{N}$ number of parameters by $\mathrm{M}$ number of values is (2) a matrix is obtained. After that, in order to check correlation relationship between vectors that creates (2) matrices reciprocal correlation coefficients are calculated. For this purpose:

Average value of every vectors' elements

$$
\mu_{n}=\frac{1}{M} \sum_{k=1}^{M} P_{n k}, \quad \mathrm{n} \in[1, \mathrm{~N}]
$$

Average square difference ofevery vector elements

$$
\sigma_{\mathrm{n}}=\sqrt{\frac{1}{\mathrm{M}} \sum_{\mathrm{k}=1}^{\mathrm{M}}\left[\mathrm{P}_{\mathrm{nk}}-\mu_{\mathrm{n}}\right]^{2}}, \quad \mathrm{n} \in[1, \mathrm{~N}]
$$

Correlation between two $\mathrm{i}$-th and $\mathrm{j}$-th vector

$$
\sigma_{i j}=\frac{1}{M} \sum_{k=1}^{M}\left(P_{i k}-\mu_{i}\right)\left(P_{j k}-\mu_{j}\right), \quad i, j \in[1, N]
$$

Correlation coefficient between two $\mathrm{i}$-th and $\mathrm{j}$-th vector

$$
\rho_{\mathrm{ij}}=\sigma_{\mathrm{ij}} /\left(\sigma_{\mathrm{i}} \sigma_{\mathrm{j}}\right) \quad[10]
$$

Obtained correlation coefficientsalsocreates correlation coefficient matrices.

$$
\rho=\left(\begin{array}{ccc}
\rho_{11} & \cdots & \rho_{1 \mathrm{M}} \\
\vdots & \ddots & \vdots \\
\rho_{\mathrm{N} 1} & \cdots & \rho_{\mathrm{NM}}
\end{array}\right)
$$

(3) in every row of correlation coefficient matrice different indexes, among elements which are not situated along diagonal by keeping the largest element, effectiveness indicator parameters which has statical relations among each other can be determined. Assume that,by this method $\mathrm{K}$ number of parameters that is between $3<\mathrm{K}<\mathrm{N}$ is selected. Newly selected $\mathrm{K}$ number of parameters' value creates following matrix which has $\mathrm{K}$ number of rows: 


$$
\mathrm{P}=\left(\begin{array}{ccc}
\mathrm{P}_{11} & \cdots & \mathrm{P}_{1 \mathrm{M}} \\
\vdots & \ddots & \vdots \\
\mathrm{P}_{\mathrm{K} 1} & \cdots & \mathrm{P}_{\mathrm{KM}}
\end{array}\right)
$$

During internet advertising campaign and experiments carried out on advertisement sites every selected indicator parameters' importance, weight of dynamic changes Iternet advertising maketing information can be determined. Assume that, these weights,

On the condition of $\sum_{j=1}^{K} w_{j}=1$,

vector can be written as $\left(\mathrm{w}_{1}, \mathrm{w}_{2}, \ldots, \mathrm{w}_{\mathrm{K}}\right)$.

If we multiply weight vector to (4) matrix one integral parameter values can be obtained [11]:

$$
\left(\mathrm{w}_{1}, \mathrm{w}_{2}, \ldots, \mathrm{w}_{\mathrm{K}}\right) *\left(\begin{array}{ccc}
\mathrm{P}_{11} & \ldots & \mathrm{P}_{1 \mathrm{M}} \\
\cdot & . & \cdot \\
\mathrm{P}_{\mathrm{K} 1} & \ldots & \mathrm{P}_{\mathrm{KM}}
\end{array}\right)=\left(\mathrm{I}_{1}, \mathrm{I}_{2}, \ldots, \mathrm{I}_{\mathrm{M}}\right)
$$

Here

$\mathrm{I}_{\mathrm{m}}=\sum_{\mathrm{i}=1}^{\mathrm{K}} \mathrm{W}_{\mathrm{i}} * \mathrm{P}_{\mathrm{im}}$ is calculated in such way. By adding the obtained integral parameter to (4) matrix, more complete matrix is obtained. These every parameters can be used forevaluation of effectiveness of Internet advertisement campaign.

\section{CReation of Models for Evaluation of Dynamic CHANGE OF INTERNET ADVERTISEMENT CAMPAIGN}

It is known that, in order to evaluate empric, socialeconomic researches' results, as well as effectiveness of Internet advertising campaign mathematical methods are applied. For this purpose, operations are carried out in appropriate to researches on results obtained from experiments[12-14].

For creation of evaluation models of effectiveness of Internet advertisement campaign, control of changes of selected parameters' values started at $\mathrm{T}_{0}=0$ time, Internet advertisement campaign starts at $\mathrm{T}_{1}$, end of the campaing time is $T_{2}$ the starting of parameters' value reaching previous values at $\mathrm{T}_{3}$ time and general monitoring time $\left[\mathrm{T}_{0}, \mathrm{~T}\right]$ can be accepted. By practical experiments during succesfull İnternet advertisement campaigns monitoring, change in parameters' values as dependence on time $\mathrm{P}(\mathrm{t})$ can be given such as in the Picture 1 .

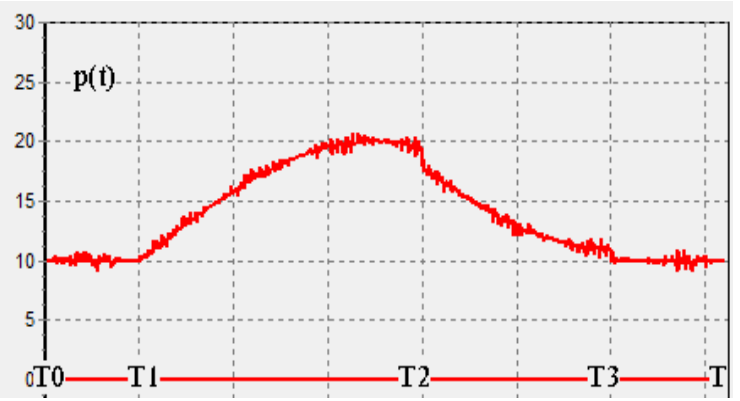

Fig.1. During monitoring of succesfull advertisement campaign effectiveness parameters' values graph of time dependence.
As seen, until starting time $\mathrm{T}_{1}$ of advertisement campaign, change of parameters can be considered as constant. After the started time $\mathrm{T}_{1}$ of advertisement campaign the price starts to rise. This rise continiued till $\mathrm{T}_{2}$ time and then started to decrease. Therefore, $\mathrm{T}_{2}$ time is called ending time of Internet advertisement campaign. This decrease approximately continiued from start of Internet advertisement campaign till previous value. As seen in the picture, change in values of parameter is not smooth. One of the reason is related to inaccurately obtaining information in advertisement sites in Internet environment and calculation errors. While creating models for dynamic evaluation of Internet advertisement camapign effectiveness these kind of deviations are removed.

Experimental values can be written as analytical function in every piece. At this time, as deviations and inaccuracies created by various reasons in experimental values are removed. Operations on the obtained analytical function necessary can be simplified. For the solution of this issue appropriate method for every pieces should be applied.

In the first $\left[\mathrm{T}_{0}, \mathrm{~T}_{1}\right]$ piece, $\mathrm{P}_{1}(\mathrm{t})=\mathrm{C}$, here $\mathrm{C}$ can be taken as constant as average values of $\mathrm{P}$ on piece of $\left[\mathrm{T}_{0}, \mathrm{~T}_{1}\right]$.

In second $\left[\mathrm{T}_{1}, \mathrm{~T}_{2}\right]$ semiinterval $\mathrm{P}_{2}(\mathrm{t})=\mathrm{a}_{2} \mathrm{t}^{2}+\mathrm{b}_{2} \mathrm{t}+$ $c_{2}$ function can be given. Square trinomial coefficients can be determined as following:

Values involved in $\left(T_{1}, T_{2}\right]$ semiinterval, lets write as sequence of $\mathrm{P}_{21}, \mathrm{P}_{22}, \ldots, \mathrm{P}_{2 \mathrm{R}}$. Here first index show the values belong to second semiinterval. The value of $R$ is founded as the largest $R$ on the condition of $T_{1}+R \leq T_{2}$. Square trinomial coefficient should be founded such a way that, the values obtained by giving the function to arguments $t_{r}=T_{0}+r, r \in[1, R]$ the values, the square differece between the obtained values between sequence value to be the smallest one. If we write average square difference as $\mathrm{E}=\frac{1}{\mathrm{R}} \sum_{\mathrm{r}=1}^{\mathrm{R}}\left(\mathrm{P}\left(\mathrm{t}_{\mathrm{r}}\right)-\mathrm{P}_{2 \mathrm{r}}\right)^{2}$ and take into consideration mentioned above, we will see that, average square difference depend on trinomial coefficient. Therefore, searched coefficient

$$
\left\{\begin{array}{l}
\frac{\vartheta \mathrm{E}}{\vartheta \mathrm{a}_{2}}=0 \\
\frac{\vartheta \mathrm{E}}{\vartheta \mathrm{b}_{2}}=0 \\
\frac{\vartheta \mathrm{E}}{\vartheta \mathrm{c}_{2}}=0
\end{array}\right.
$$

founded as solution of the equation.

For the third $\left(\mathrm{T}_{2}, \mathrm{~T}_{3}\right]$ semiinterval, with analogical rule function $\mathrm{P}_{3}(\mathrm{t})=\mathrm{a}_{3} \mathrm{t}^{2}+\mathrm{b}_{3} \mathrm{t}+\mathrm{c}_{3}$ can be created. Thereby, during moitoring changes due to values of selected parameters according to dependence of time can be determined as follow: 


$$
P(t)=\left\{\begin{array}{lc}
P_{1}(t)=C, & t \in\left[T_{0}, T_{1}\right] \\
P_{2}(t)=a_{2} t^{2}+b_{2} t+c_{2}, & t \in\left(T_{1}, T_{2}\right] \\
P_{3}(t)=a_{3} t^{2}+b_{3} t+c_{3}, & t \in\left(T_{2}, T_{3}\right]
\end{array}\right.
$$

Obtained function can be taken as carried out dynamic changes of Internet advertisement campaign effectiveness. By using this function, separate characteristics of selected parameters.

The average value of the function on any time piece can be given as following:

$$
P_{t \in\left(T_{n}, T_{m}\right]}=\frac{1}{T_{m}-T_{n}} \int_{T_{n}}^{T_{m}} P(t) d t
$$

After $\mathrm{T}_{1}$ time that Internet advertisement campaign starts, the following coefficient for dynamic change any current $t \in\left(T_{1}, T_{2}\right]$ time can be given:

$$
\gamma_{t}=\frac{\int_{T_{1}}^{t} P(t) d t}{t-T_{1}}: \frac{\int_{T_{0}}^{T_{1}} P(t) d t}{T_{1}-T_{0}}
$$

Over time, increase of $\gamma_{\mathrm{t}}$ coefficient values indicates that İnternet advertisement campaign gives successfull results.However, decrease in amount of $\gamma_{t}$ coefficient: indicates that advertisement campaign effect is reducing. At this time, companies that ordered advertisement and interested in the results of them should carry out extra actions.

Result

In the article, a method for analysis of dynamic changes of Internet advertising marketing information is developed. At this time, in order to evaluate effectiveness of Internet advertising marketing used various indicator parameters have been analyzed. In the sequence of these indicators users who appeal such CTR, CTB Internet advertisement sites and potential customers to be interest in advertised goods and services, objective numerical values indicators of oredering of these goods and services have been analyzed. Beside this, the indicators have been analyzed for being attractive to potential customers of such CTI, VTR advertisement sites and providing them to be future customer. It is noted that, companies that offers goods and services can use information about customer, shopping operations in order to evaluate the effectiveness of conducted advertisement campaign. As a result of analysis the matrix of indicator parameters has been created. In this matrix, keeping algorithms of parameters that has statistical communication with each other. Beside this, integral indicator parameter has been created by weight coefficients that are determined by experimental way for every indicator parameter.
In order to evaluate the effectiveness of advertisement campaign, indicators that are obtained from integral indicator and as well any indicators that obtained from directly or indirectly can be used. For this purpose, if we consider any selected indicator as a time series, we will see that there are random deviations. That is why, the experimental values of selected indicators should be modelled by certain mathematical functions. During monitoring of any selected parameter, in order to build a function of time of the changes, method for minimizing the average square difference has been used. Throughout this method, the values of parameter that is during starting of the Internet advertisement campaign till end of the campaign values modelled as square trinomial. Obtained function in the result can be taken as dynamic change model of effectiveness of the Internet advertisement campaign. The importance of the model is unlike experimental values the builded function's being smooth and being released from random deviations. By using the model, the formula has been given for calculation of average values of selected parameters in any time piece. The formula has been given to determine dynamic changes measure during starting of the Internet advertisement campaign till any current time. By using given methods and obtained formula, in any current time to evaluate the effectiveness of conducted Internet advertisement campaign, necessary corrections can be done.

Algorithms and methods that are given in the article can be used as a tool in solution of analogical social economic issues.

\section{REFERENCES}

[1] J.L. Daft, Richard Theory of Organization: A Textbook for University Students Learning in the Specialty of "Organization Management". M .: UNITY-DANA, 2006. $736 \mathrm{sec}$.

[2] D. Kolpakidi Improvement of the regional tourism infrastructure. The journal of the st petersburg state economic university, 2014 No. 6, p. 64-69.

[3] E.P. Golubkov. Marketing Markets: A Textbook. Moscow: Finpress Press, 1999. - 656 s.

[4] http://www.digitalnature.com/uploads/blog/GoogleOrganicCTRStudy2014.pdf

[5] http://growtraffic.com/blog/2016/09/good-click-ratepercentage

[6] https://en.wikipedia.org/wiki/CTR_(\%D0\%B8\%D0\%BD\% D1\%82\%D0\%B5\%D1\%80\%D0\%BD\%D0\%B5\%D1\%82)

[7] http://powerbranding.ru/mediastrategiya/advertising-report/

[8] http://memosales.ru/reklama/ocenka-effektivnosti-kampanii

[9] T.V. Deinekin Complex method for assessing the effectiveness of online advertising in commercial organizations. Marketing in Russia and abroad. 2003, №2. Http://www.mavriz.ru/articles/2003/2/244.html 
[10] J. Bendat, A. Pirsol. Application of correlation and spectral analysis. M: The World 1983, 312 p.

[11] C.David, D.Tom, T.Rohit and W.Andrew. A.Linear First Edition Davis California, 2013. 436 p.

[12] O.V. Egorova, Analysis of methods for evaluating the effectiveness of an advertising campaign. Http://www.rae.ru/forum2012/pdf/1419.pdf

[13] I.N. Dubina Mathematical foundations of empirical socioeconomic research: a textbook - Barnaul: Publishing house Alt. Un-ta, 2006, 263 p.

[14] http://www.netbooster.com/wp-

content/uploads/2014/11/One-click-curve-to-rule-them-allNetBooster.pdf

\section{Authors' Profiles}

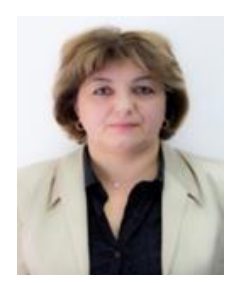

Kamala K. Hashimova Currently she is the chief of sector at the Institute of Information Technologies of ANAS.

She closely participated in the creation of "Multimedia Gallery" base of the Institute and currently is in charge there. Participated in the creation of the www.science.az portal of ANAS.

Controls data posting in the section "Institute in mass media" of www.ict.az web-site. She teaches at the Education Center of the Institute.Author of several paper.

How to cite this paper: Kamala.K.Hashimova, "Analysis Method of Internet Advertising-Marketing Information's Dynamic Changes", International Journal of Information Engineering and Electronic Business(IJIEEB), Vol.9, No.5, pp. 2833, 2017. DOI: $10.5815 / \mathrm{ijieeb.2017.05.04}$ 